OPEN ACCESS

Edited by:

Patrick R. Hot

Icahn School of Medicine at Mount

Sinai, United States

Reviewed by:

Miguel A. Gama Sosa,

James J. Peters VA Medical Center,

United States

Bogdan O. Popescu,

Carol Davila University of Medicine and Pharmacy, Romania

${ }^{*}$ Correspondence:

Franciska Erdô

erdo.franciska@itk.ppke.hu

Received: 02 May 2019

Accepted: 15 July 2019

Published: 30 July 2019

Citation:

Erdő $F$ and Krajcsi $P$

(2019) Age-Related Functional and Expressional Changes in Efflux

Pathways at the Blood-Brain Barrier.

Front. Aging Neurosci. 11:196. doi: 10.3389/fnagi.2019.00196

\section{Age-Related Functional and Expressional Changes in Efflux Pathways at the Blood-Brain Barrier}

\author{
Franciska Erdo" ${ }^{1 *}$ and Péter Krajcsi ${ }^{1,2,3}$ \\ ${ }^{1}$ Faculty of Information Technology and Bionics, Pázmány Péter Catholic University, Budapest, Hungary, ${ }^{2}$ Solvo \\ Biotechnology, A Charles River Company, Budapest, Hungary, ${ }^{3}$ Faculty of Health Sciences, Semmelweis University, \\ Budapest, Hungary
}

During the last decade, several articles have reported a relationship between advanced age and changes in the integrity of the blood-brain barrier (BBB). These changes were manifested not only in the morphology and structure of the cerebral microvessels but also in the expression and function of the transporter proteins in the luminal and basolateral surfaces of the capillary endothelial cells. Age-associated downregulation of the efflux pumps ATP-binding cassette transporters (ABC transporters) resulted in increased permeability and greater brain exposure to different xenobiotics and their possible toxicity. In age-related neurodegenerative pathologies like Alzheimer's disease $(A D)$, the amyloid- $\beta$ ( $A \beta$ ) clearance decreased due to P-glycoprotein (P-gp) dysfunction, leading to higher brain exposure. In stroke, however, an enhanced P-gp function was reported in the cerebral capillaries, making it even more difficult to perform effective neuroprotective therapy in the infarcted brain area. This mini-review article focuses on the efflux functions of the transporters and receptors of the BBB in age-related brain pathologies and also in healthy aging.

Keywords: blood-brain barrier, aging, efflux transporters, P-glycoprotein, BCRP, Alzheimer's disease, Parkinson's disease, stroke

\section{INTRODUCTION}

The blood-brain barrier (BBB) is a defensive structure and mechanism of the cerebral capillaries which works against chemical and microbial agents which could endanger the finely-regulated brain homeostasis (Erdo" et al., 2017). The most important elements of the BBB are the capillary endothelial cells, which are connected by tight junctions (TJs) and adherens junctions (AJ) and surrounded by the basal membrane (Ceafalan et al., 2019), pericytes, and astrocyte endfeet. The paracellular transport of xenobiotics is blocked by occludin, claudin, and junctional adhesion molecule (JAM) proteins, connected to zonula occludens (ZO) proteins 1,2 , and 3 , respectively. The AJ proteins (nectin and cadherins) also play an important role in the blockade of intercellular transport. The efflux transporter proteins expressed on the luminal surface of endothelial cells (Figure 1) amplify the protection provided by the compact cellular layers of brain microvessels and regulates the transcellular transport. These 
proteins transport their substrates against the concentration gradient back into the cerebral circulation and this way they can protect the brain parenchyma from dangerous molecules.

The BBB mediates a bidirectional transport of molecules (Figure 1). For small molecules, the major players are the transporters/carriers. For larger molecules such as peptides, receptor mediated pathways also contribute to transport (Figure 1).

This process is affected by aging. Both the expression level and the functionality of ATP binding cassette transporter proteins ( $\mathrm{ABC}$ transporters) go through a transformation in aged subjects under both physiological and pathological conditions. The data in the literature available on these transformations are briefly summarized in this article. Paracellular permeability is also affected by physiological and pathological aging. Since it has been covered in detail in recent reviews (Storck et al., 2018), however, it is not covered in the present review article.

\section{EFFLUX FUNCTIONS IN BRAIN MICROVESSELS}

In Abcbla/Mdrla knockout mice, brain concentration of Mdrla substrate ivermectin increased 87 -fold, while plasma concentration increased only 3.3-fold (Schinkel et al., 1994). This increase of ivermectin brain exposure showed the pivotal importance of Abcbla in the BBB and was in good agreement with the 50-100-fold increase in neurotoxicity of the drug (Schinkel et al., 1994). ABCB1/Abcb1a is localized in the luminal membrane of the BBB endothelial cells (Roberts et al., 2008). As it displays a broad substrate specificity, it provides significant protection to the brain.

ABCG2/BCRP/Abcg2/Bcrp1 is another luminally localized efflux transporter thought to play a major role in protecting the brain against toxicants. ABCG2/Abcg2 and ABCB1/Abcb1a have overlapping substrate specificities and thus may provide dual protection against toxicants, as shown by studies utilizing knockout mice (Agarwal et al., 2011). In double knockouts brain exposure to a substrate drug has often been found $>10$-fold greater than brain exposure in wild type animals, and a synergistic effect has been suggested. A detailed kinetic analysis of Abcbla and Abcg2 function has shown that double knockouts over-predict drug-induced inhibition of both transporters, as clinically relevant concentrations of perpetrators are not likely to yield complete inhibition of $A B C B 1$ and ABCG2 (Kalvass et al., 2013). Complete consensus on the potential risk of $\mathrm{ABCB} 1$ and $\mathrm{ABCG}$-mediated drug-drug interaction at the BBB has still not been reached, as it has been claimed that for victim drugs (such as several antivirals with high-fraction transported values), a potential for a clinically significant increase in brain exposure may occur (Prasad and Unadkat, 2015). It is also of note that $A B C B 1$ inhibition yielded greater increases in brain distribution of dual substrate $\left[{ }^{11} \mathrm{C}\right]$ tariquidar in patients carrying one copy of the functionally impaired allele (c.421CA genotypes) of ABCG2 than in wild-type patients (c.421CC genotype; Bauer et al., 2016b). ABCB1 and ABCG2 cover a broad substrate specificity range. In addition to hydrophobic substrates,
$\mathrm{ABCB} 1$ transports cationic drugs and ABCG2 transports many acidic drugs (Sedykh et al., 2013).

ABCC4/MRP4/Abcc4/Mrp4 is the third major efflux transporter expressed in the BBB (Table 1). Localization of ABCC4 is somewhat ambiguous as it was shown to be expressed in both the luminal and abluminal membranes of the $\mathrm{BBB}$ endothelium of the bovine brain microcapillary endothelium (Zhang et al., 2004). In contrast, in humans, it has only been detected in the luminal membrane (Nies et al., 2004). ABCC4 preferentially transports amphiphilic anions such as prostaglandins, steroid and bile salt metabolites, and drugs such as Ro-64-0802 the pharmacologically active form of oseltamivir (Ose et al., 2009).

Quantifiable expression of $\mathrm{ABCA} 2$ and $\mathrm{ABCA} 8$ in the $\mathrm{BBB}$ endothelial cells has been also reported (Table 1). ABCA2 is an endolysosomal protein and plays a pivotal role in the homeostasis of various lipids (Davis and Tew, 2018). As such, it has been linked to Alzheimer's disease (AD; Davis, 2015). ABCA8 is also a lipid transporter and has been implicated in various brain pathologies (Jha et al., 2019). The location of ABCA8 in the $\mathrm{BBB}$ is not known. It is sinusoidally localized in hepatocytes (Sasaki et al., 2018).

Lipoprotein receptor-related protein-1 (LRP-1) also contributes to brain efflux of amyloid- $\beta$ (A $\beta$ ) peptide (Shibata et al., 2000). Therefore, it is often discussed along with ABCB1 with regard AD and aging (Osgood et al., 2017). A strong expression of the protein in the abluminal membrane has been reported in both rats (Osgood et al., 2017) and mice (Ma et al., 2018; Storck et al., 2018).

Among efflux transporter proteins quantified by proteomics, Abcbla is the most abundant in rats and mice (Table 1). In monkeys as well as dogs, ABCG2/Abcg2 is significantly more abundant, and in humans, the expression of the two transporters is close to the same (Table 1). Therefore, it is likely that the dominant role of Abcb1a over Abcg2 shown in mice (Kodaira et al., 2010) would not directly translate into humans.

Small regional differences in transporter expression have also been observed. The human expression of ABCG2 and ABCB1 was about $40 \%$ greater in the occipital lobe than in the parietal lobe (Billington et al., 2019). In the canine brain, regional differences in Abcg2 protein expression levels were reported for the cerebellum and the brain stem (Braun et al., 2017).

The abundance of $A B C B 1$ was lower in men than in women (Billington et al., 2019). This, however, did not lead to a statistically significantly greater brain distribution of ABCB1 substrate $\left[{ }^{11} \mathrm{C}\right]$ verapamil (Sasongko et al., 2005).

\section{METHODS OF STUDYING EFFLUX TRANSPORTER EXPRESSION AND FUNCTION IN THE BBB}

Early on, gene expression was studied at the mRNA level by qRT-PCR (Osgood et al., 2017; Bors et al., 2018). Expression testing by western blot was also common (Rosati et al., 2003; Osgood et al., 2017; Bors et al., 2018). Immunohistochemistry provides localization data and has been 


\section{Blood}

luminal / apical membrane

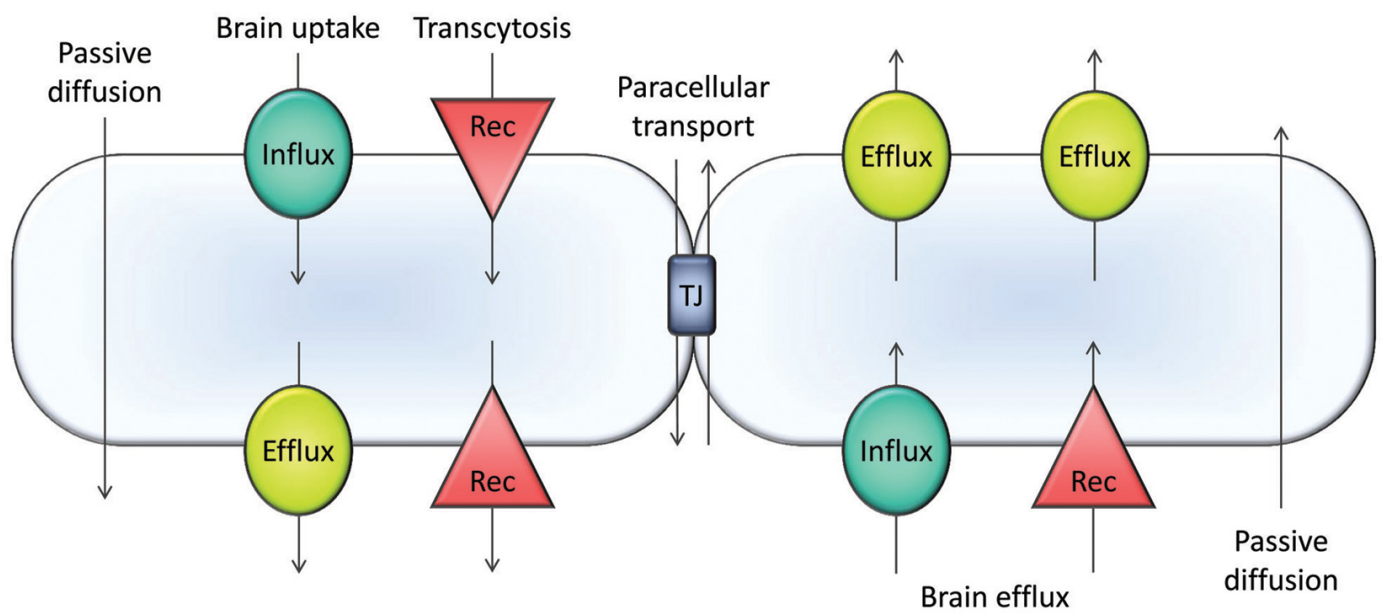

abluminal / basolateral membrane

Brain

FIGURE 1 | Major transport pathways at the blood-brain barrier (BBB). Transcellular transport occurs by passive diffusion or is mediated by influx and efflux transporters/carriers and/or receptors (Rec). Passive diffusion can be bidirectional; however, it is most often a blood-to-brain transport utilized by intermediate/high passive-permeability drugs. Paracellular transport is only significant for small compounds ( $M W<250 \mathrm{Da}$ ).

frequently used despite challenges in quantitation of the data. The contemporary approach is quantitative LC-MS/MS-based proteomics (Table 1).

To study efflux transporter function in rodents, microdialysis (Sziráki et al., 2011, 2013; Bors et al., 2018) and SPECT imaging (Bors et al., 2018) has been utilized. Quinidine is the typical ABCB1 probe for microdialysis studies (Sziráki et al., 2011, 2013; Bors et al., 2018), and applicability of (99mTechnetium)2-methoxy-isobutyl-isonitrile (MIBI) as an $\mathrm{ABCB} 1$ probe in SPECT studies has been demonstrated (Bors et al., 2018).

With the advent of position-emission computed tomography (PET-CT), functional testing of efflux transporters in the human BBB has become common (Toornvliet et al., 2006; Bartels et al., 2009; Bauer et al., 2009; Syvänen and Eriksson, 2013; Liow et al., 2016). $\left[{ }^{11} \mathrm{C}\right]$ Verapamil has been the $\mathrm{ABCB} 1 / \mathrm{P}$ glycoprotein (P-gp) selective probe substrate most commonly used in the studies and the applicability of $\left[{ }^{11} \mathrm{C}\right]$ Loperamide as well as $\left[{ }^{11} \mathrm{C}\right]$ Desmethylloperamide has also been demonstrated (Syvänen and Eriksson, 2013). Probes such as $\left[{ }^{11} \mathrm{C}\right]$ Elacridar and $\left[{ }^{11} \mathrm{C}\right]$ Tariquidar are dual substrates of $\mathrm{ABCB} 1$ and $\mathrm{ABCG} 2$ (Syvänen and Eriksson, 2013; Bauer et al., 2016a), and $\left[{ }^{18} \mathrm{~F}\right] \mathrm{FCW}$ AY is transported by ABCB1, ABCG2 and ABCC1 (Liow et al., 2016).

\section{EXPRESSION OF EFFLUX PATHWAYS UPON PHYSIOLOGICAL AGING}

Expression and functional studies show a nice correlation between $\mathrm{ABCB} 1$ expression and function, as both show a decrease with physiological aging (Toornvliet et al., 2006; Bartels et al., 2009; Billington et al., 2019). Data on the effect of aging on expression of efflux transporters in humans has come from studies on postmortem tissue (Billington et al., 2019). Functional studies are more frequent, where PET-CT is used. One study in humans has shown gender specificity, as decreased function was seen only in men (van Assema et al., 2012). In dogs, a $72 \%$ drop in ABCB1 expression in animals older than 100 months over animals in the 23-36 month age group has been reported (Pekcec et al., 2011). A decrease in Abcla expression and function in rats has also been reported (Rosati et al., 2003).

Data generated on SAMP8 in senescence-accelerated mice have shown increased expression of Abcbla (Wu et al., 2009). However, data on BBB permeability is controversial in these animals, as increased permeability (Ueno et al., 1993; Pelegrí et al., 2007) and the lack of increase (Banks et al., 2000) have both been reported. Increase in Abcbla expression would lead to an increased function that would be counterintuitive with increased permeability. As data in all species but mice have shown a decreased ABCB1 expression and function with age it is tempting to suggest that it is a general phenomenon across species and mice is not a good model for humans or accelerated aging does not correctly model all aspects of physiological aging.

$\mathrm{ABCG}$ /BCRP is the other major efflux transporter luminally expressed in $\mathrm{BBB}$ endothelial cells, but no data have been reported on the effect of physiological aging on BCRP expression and/or function in the BBB. Changes in liver expression of ABCG2 upon aging have been studied, where no difference in 
mRNA levels but a decreased expression at the protein level has been shown (Riches et al., 2015).

In a rat model of aging, LRP1 expression on the basal surface of the BBB endothelium was robust in 3-month-old animals, but significantly reduced in 34-month-old animals (Osgood et al., 2017). A reduction in LRP1 mRNA levels in cerebral microvessels was also demonstrated in the same study.

\section{MECHANISM OF REGULATION OF TRANSPORTER EXPRESSION IN AGING}

The studies aiming to explore the mechanism of $A B C B 1$ expression in humans have almost unanimously shown decreased protein expression and function in aging (see previous section for details). Levels of ABCB1 mRNA, however, have not always showed a decrease with age within the same study (Chiu et al., 2015).

In rats, the one study that covered Abcbla expression at the level of both mRNA and protein found a parallel decrease in the two functions (Osgood et al., 2017). In the SAMP8 mice, Abcbla mRNA levels increased more significantly than Abcbla protein levels (Wu et al., 2009), but applicability of that model is questionable as this is the only model that shows an increased protein expression upon physiological aging (see previous section for details).

One study has addressed the mechanism of down-regulation of $\mathrm{ABCB} 1$. However, since patients with $\mathrm{AD}$ were also included in that study (Hartz et al., 2018), it is difficult to draw conclusions on the mechanism of the decrease of $\mathrm{ABCB} 1$ protein upon only physiological aging. In humans with $\mathrm{AD}$, the levels of ubiquitination was greater than in age-matched cognitively normal humans (Hartz et al., 2018). Increased ubiquitination was also observed in transgenic human amyloid precursor protein (hAPP)-overexpressing mice (Tg2576) in the same study. It was also shown that PYR41, a cell-permeable, irreversible inhibitor of the ubiquitin-activating enzyme E1 inhibited ubiquitination, counteracted the decrease of Abcbla and reduced $A \beta$ plaque formation in the transgenic mice. Importantly, no decrease of LRP-1 activity in hAPP mice was observed (Hartz et al., 2018).

\section{EFFLUX PUMPS AT THE BBB IN AGE-RELATED PATHOLOGICAL CONDITIONS}

Aged people are at higher risk of medicine-induced toxicities resulting from either increased drug sensitivity or age-related pharmacokinetic changes. The situation is further complicated with the two most prevalent age-related neurodegenerative diseases, $\mathrm{AD}$ and Parkinson's disease (PD), for both of which there is growing evidence of altered structure and function of the $\mathrm{BBB}$, including downregulation of $\mathrm{TJ}$ proteins and efflux transporters such as P-gp (Bors et al., 2018). These alterations would have an impact on CNS drug exposure and the risk of neurotoxicity from systemically-acting drugs (Erdo" et al., 2017; Pan and Nicolazzo, 2018). Qosa et al. (2016) have summarized the directions of the efflux transporter alterations at the $\mathrm{BBB}$ in different neurodegenerative disorders. They showed that P-gp 
is downregulated in $\mathrm{AD}$, Creutzfeldt-Jakob syndrome, multiple sclerosis, brain tumors, PD, and schizophrenia, while it is upregulated in amyotrophic lateral sclerosis, epilepsy, stroke, and ischemic brain injuries. There are many unanswered questions about the role of BCRP, MRP1, and MRP2 in neurodegenerative diseases (Qosa et al., 2016). In the next paragraphs only the three most important examples are shown in more details.

\section{Alzheimer's Disease}

The involvement of transporters located at the BBB has been suggested in the control of cerebral $A \beta$ levels, and thereby in $A D$. Active transport of $A \beta$ across the $B B B$ seems to involve a number of transporters that control the level of the soluble isoform of $A \beta$ in brain. P-gp contributes to the efflux of brain-derived $A \beta$ into blood (Kuhnke et al., 2007; Bell and Zlokovic, 2009; Hartz et al., 2010; Brenn et al., 2011; Vogelgesang et al., 2011; Sagare et al., 2012; Sharma et al., 2012; Erdo" et al., 2017). It seems that, in addition to the age-related decrease of P-gp expression, $A \beta 1-42$ itself downregulates the expression of $\mathrm{P}$-gp and other $\mathrm{A} \beta$ transporters, which could exacerbate the intracerebral accumulation of $A \beta$ and thereby accelerate neurodegeneration in $\mathrm{AD}$ and cerebral $\mathrm{A} \beta$ angiopathy. Systemic inflammation by lipopolysaccharide triggers defects in P-gp-mediated $\mathrm{A} \beta$ clearance from the brain and leads to its accumulation (Ravenstijn et al., 2008). Reduction of P-gp expression and transport activity has been found in isolated capillaries as a result of $\mathrm{A} \beta 40$ mediated P-gp ubiquitination, internalization, and proteasome-dependent degradation (Hartz et al., 2016). However, little is known about the regulation of these transporters at the BBB (Do et al., 2016) in animal models of $\mathrm{AD}$. The most efficient therapeutic strategy for limiting the accumulation of $A \beta$ in the brain as early as possible in disease development could be to block $\mathrm{A} \beta$ influx by inhibiting Rage and/or Oatp1a4, or to stimulate the synthesis and/or function of Abcal and/or Abcg4 at the BBB (Do et al., 2016).

\section{Parkinson's Disease}

The brain distribution of compounds with different transport mechanisms across the BBB (1-3,4-dihydroxyphenylalanine, carbamazepine, quinidine, lovastatin, and simvastatin) in healthy and MPTP-treated macaques have been studied. Thiollier et al. (2016) found only changes in the distribution of quinidine, indicating changes in P-gp functionality. In contrast, studies performed by Hou et al. (2014) suggest that P-gp inhibition increases BBB permeability to $\mathrm{N}$-[2-(4-hydroxy-phenyl)-ethyl]2-(2,5-dimethoxyphenyl)-3-(3-methoxy-4-hydroxy-phenyl)acrylamide (FLZ), a novel synthetic squamosamide derivative and potential anti-PD agent. No significant differences were observed, however, in the brain distribution of FLZ between normal and PD model rats, suggesting no significant change in P-gp in PD (Hou et al., 2014). Bartels et al. (2008a,b) investigated in vivo $\mathrm{BBB} \mathrm{P}$-gp function in patients with parkinsonian neurodegenerative syndromes using $\left[{ }^{11} \mathrm{C}\right]$ verapamil PET. Advanced PD patients had increased $\left[{ }^{11} \mathrm{C}\right]$ verapamil uptake in frontal white matter regions compared with controls. The authors concluded that lower $\left[{ }^{11} \mathrm{C}\right]$ verapamil uptake in midbrain and frontal regions of de novo PD patients could indicate a regional up-regulation of P-gp function (Bartels et al., 2008b). However, in a later study by this group, the decreased BBB P-gp function in early-stage PD patients could not be confirmed (Bartels et al., 2008a).

\section{Stroke}

Stroke risk increases with aging, and one-third of ischemic strokes occur in the very elderly ( $>$ or $=80$ years). These are responsible for two-thirds of the overall stroke-related morbimortality (Ly and Maquet, 2014).

Rats subjected to middle cerebral artery occlusion (MCAO) for $90 \mathrm{~min}$ and killed at $4,14,24$, and $48 \mathrm{~h}$ postreperfusion onset were studied to determine the time course of P-gp expression. To mimic ischemia occurring at the $\mathrm{BBB}$, rat brain endothelial (RBE4) cells were subjected to hypoxia and low glucose (HLG) for $16 \mathrm{~h}$. Immunoblotting analyses showed P-gp increases in brain and liver following 90-min MCAO, as well as in cultured RBE4 cells after 16-h HLG treatment. The increase in P-gp could dramatically reduce the bioavailability and efficacy of neuroprotective drugs. P-gp, therefore, represents a big hurdle in drug delivery to the ischemic brain (DeMars et al., 2017).

\section{CONCLUSIONS AND OUTLOOK}

Transporter proteomics has been used in the past decade to study expression in the BBB, but mostly from a perspective of drug exposure (Uchida et al., 2011a; Trapa et al., 2019), and many questions on the effect of aging and disease on efflux transporter expression and function are still open. The physiology and pathophysiology, as well as the cell biology and biochemistry of transport, are new fields. One uncertainty is the correlation of expression and activity of efflux proteins. In general, it is assumed that protein expression and activity for ABCB1 and ABCG2 correlate (Uchida et al., 2011a; Trapa et al., 2019). However, it is not always the case when mRNA levels and function have been monitored (Vilas-Boas et al., 2011). In some studies, discrepancies between protein expression and function have also been reported (Poller et al., 2010).

It is reasonable to assume that a complex interplay of age-related decrease and a disease-related stimulation shapes the expression profile of efflux transporters. Indeed, a biphasic regulation of $A B C B 1$ in $A D$ has been suggested (Vogelgesang et al., 2004). Also, ABCB1 and ABCG2 expression by neuroinflammatory stimuli displayed a complex pattern (von Wedel-Parlow et al., 2009). Inhibition of efflux function at the time when it plays a protective role is counterintuitive. In contrast, the inhibition of efflux functions to enhance the BBB permeability for drug delivery may make sense. The time dependence of pathophysiological changes must be pinned down to utilize the data to drive pharmaceutical and nutraceutical research.

In addition to temporal changes, regional variance (Deo et al., 2014; Kannan et al., 2017) in the expression of transporters is a factor to consider. Both could be monitored with imaging. However, $\left[{ }^{11} \mathrm{C}\right]$ verapamil is not an ideal probe for $\mathrm{ABCB} 1$, due to its lipophilicity (Luurtsema et al., 2016). Development of 
novel probes or employment of drug probes used for preclinical species could enable the scientific community to address these issues. ${ }^{18} \mathrm{~F}$-FCWAY is a weak substrate of $\mathrm{ABCB} 1$ and has been suggested as a probe to address both up- and down-regulation of ABCB1 transport activities (Liow et al., 2016).

Therapeutic strategies must also take into account the fact that expression of proteins such as ABCA2 show an inverse correlation with disease (Michaki et al., 2012). Strategies based on the modulation of transporter expression must, therefore, use selective inducers/repressors to provide therapeutic efficacy. Induction of proteins that slow disease progression (e.g., $\mathrm{ABCB} 1$ ) without induction of proteins (e.g., ABCA2) that facilitate disease progression is one possible strategy. $\mathrm{ABCB} 1$ and $\mathrm{ABCA} 2$ display inverse regulation upon the differentiation of colon tumors (Ohtsuki et al., 2007). However, it remains to be tested if agonists of the pregnane $\mathrm{X}$ receptor (PXR) that induce $\mathrm{ABCB} 1$ expression have a favorable induction/repression profile

\section{REFERENCES}

Agarwal, S., Hartz, A. M., Elmquist, W. F., and Bauer, B. (2011). Breast cancer resistance protein and P-glycoprotein in brain cancer: two gatekeepers team up. Curr. Pharm. Des. 17, 2793-2802. doi: 10.2174/1381612117974 40186

Agarwal, R., Hennings, L., Rafferty, T. M., Letzig, L. G., McCullough, S., James, L. P., et al. (2012). Acetaminophen-induced hepatotoxicity and protein nitration in neuronal nitric-oxide synthase knockout mice. J. Pharmacol. Exp. Ther. 340, 134-142. doi: 10.1124/jpet.111.184192

Al-Majdoub, Z. M., Al Feteisi, H., Achour, B., Warwood, S., Neuhoff, S., RostamiHodjegan, A., et al. (2019). Proteomic quantification of human blood-brain barrier SLC and $\mathrm{ABC}$ transporters in healthy individuals and dementia patients. Mol. Pharm. 16, 1220-1233. doi: 10.1021/acs.molpharmaceut.8b01189

Banks, W. A., Farr, S. A., and Morley, J. E. (2000). Permeability of the bloodbrain barrier to albumin and insulin in the young and aged SAMP8 mouse. J. Gerontol. A Biol. Sci. Med. Sci. 55, B601-B606. doi: 10.1093/gerona/55. 12.6601

Bartels, A. L., Kortekaas, R., Bart, J., Willemsen, A. T., de Klerk, O. L., de Vries, J. J., et al. (2009). Blood-brain barrier P-glycoprotein function decreases in specific brain regions with aging: a possible role in progressive neurodegeneration. Neurobiol. Aging 30, 1818-1824. doi: 10.1016/j.neurobiolaging.2008.02.002

Bartels, A. L., van Berckel, B. N., Lubberink, M., Luurtsema, G., Lammertsma, A. A., and Leenders, K. L. (2008a). Blood-brain barrier P-glycoprotein function is not impaired in early Parkinson's disease. Parkinsonism Relat. Disord. 14, 505-508. doi: 10.1016/j.parkreldis.2007. 11.007

Bartels, A. L., Willemsen, A. T., Kortekaas, R., de Jong, B. M., de Vries, R., de Klerk, O., et al. (2008b). Decreased blood-brain barrier P-glycoprotein function in the progression of Parkinson's disease, PSP and MSA. J. Neural Transm. 115, 1001-1009. doi: 10.1007/s00702-008-0030-y

Bauer, M., Blaickner, M., Philippe, C., Wadsak, W., Hacker, M., Zeitlinger, M., et al. (2016a). Whole-body distribution and radiation dosimetry of ${ }^{11} \mathrm{C}-$ elacridar and ${ }^{11} \mathrm{C}$-tariquidar in humans. J. Nucl. Med. 57, 1265-1268. doi: $10.2967 /$ jnumed.116.175182

Bauer, M., Romermann, K., Karch, R., Wulkersdorfer, B., Stanek, J., Philippe, C., et al. (2016b). Pilot PET study to assess the functional interplay between ABCB1 and ABCG2 at the human blood-brain barrier. Clin. Pharmacol. Ther. 100, 131-141. doi: 10.1002/cpt.362

Bauer, M., Karch, R., Neumann, F., Abrahim, A., Wagner, C. C., Kletter, K., et al. (2009). Age dependency of cerebral P-gp function measured with $(R)-\left[{ }^{11} \mathrm{C}\right]$ verapamil and PET. Eur. J. Clin. Pharmacol. 65, 941-946. doi: 10.1007/s00228-009-0709-5

Bell, R. D., and Zlokovic, B. V. (2009). Neurovascular mechanisms and bloodbrain barrier disorder in Alzheimer's disease. Acta Neuropathol. 118, 103-113. doi: 10.1007/s00401-009-0522-3 on transporters and receptors also involved in pathogenesis of neurodegenerative diseases.

\section{AUTHOR CONTRIBUTIONS}

FE and PK contributed equally to this manuscript. Both authors conceived, revised, and approved the final manuscript.

\section{FUNDING}

This work was supported by the European Union through grant no. EFOP-3.6.3-VEKOP-16-2017-00002, co-financed by the European Social Fund and project no. ED_17-1-20170009, and has been implemented with support provided by the National Research, Development, and Innovation Fund of Hungary, financed under the National Bionics Program funding scheme.

Billington, S., Salphati, L., Hop, C., Chu, X., Evers, R., Burdette, D., et al. (2019). Interindividual and regional variability in drug transporter abundance at the human blood-brain barrier measured by quantitative targeted proteomics. Clin. Pharmacol. Ther. 106, 228-237. doi: 10.1002/cpt.1373

Bors, L., Toth, K., Toth, E. Z., Bajza, A., Csorba, A., Szigeti, K., et al. (2018). Agedependent changes at the blood-brain barrier. A Comparative structural and functional study in young adult and middle aged rats. Brain Res. Bull. 139, 269-277. doi: 10.1016/j.brainresbull.2018.03.001

Braun, C., Sakamoto, A., Fuchs, H., Ishiguro, N., Suzuki, S., Cui, Y., et al. (2017). Quantification of transporter and receptor proteins in dog brain capillaries and choroid plexus: relevance for the distribution in brain and CSF of selected BCRP and P-gp substrates. Mol. Pharm. 14, 3436-3447. doi: 10.1021/acs. molpharmaceut.7b00449

Brenn, A., Grube, M., Peters, M., Fischer, A., Jedlitschky, G., Kroemer, H. K., et al. (2011). $\beta$-amyloid downregulates MDR1-P-glycoprotein (Abcb1) expression at the blood-brain barrier in mice. Int. J. Alzheimers Dis. 2011:690121. doi: 10.4061/2011/690121

Ceafalan, L. C., Fertig, T. E., Gheorghe, T. C., Hinescu, M. E., Popescu, B. O., Pahnke, J., et al. (2019). Age-related ultrastructural changes of the basement membrane in the mouse blood-brain barrier. J. Cell. Mol. Med. 23, 819-827. doi: $10.1111 /$ jcmm. 13980

Chiu, C., Miller, M. C., Monahan, R., Osgood, D. P., Stopa, E. G., and Silverberg, G. D. (2015). P-glycoprotein expression and amyloid accumulation in human aging and Alzheimer's disease: preliminary observations. Neurobiol. Aging 36, 2475-2482. doi: 10.1016/j.neurobiolaging.2015. 05.020

Davis, W. Jr. (2015). The ATP-binding cassette transporter-2 (ABCA2) overexpression modulates sphingosine levels and transcription of the amyloid precursor protein (APP) gene. Curr. Alzheimer Res. 12, 847-859. doi: 10.2174/156720501209151019105834

Davis, W. Jr., and Tew, K. D. (2018). ATP-binding cassette transporter-2 (ABCA2) as a therapeutic target. Biochem. Pharmacol. 151, 188-200. doi: 10.1016/j.bcp. 2017.11.018

DeMars, K. M., Yang, C., Hawkins, K. E., McCrea, A. O., Siwarski, D. M., and Candelario-Jalil, E. (2017). Spatiotemporal changes in p-glycoprotein levels in brain and peripheral tissues following ischemic stroke in rats. J. Exp. Neurosci. 11:1179069517701741. doi: 10.1177/1179069517701741

Deo, A. K., Borson, S., Link, J. M., Domino, K., Eary, J. F., Ke, B., et al. (2014). Activity of P-glycoprotein, a $\beta$-amyloid transporter at the blood-brain barrier, is compromised in patients with mild Alzheimer disease. J. Nucl. Med. 55, 1106-1111. doi: 10.2967/jnumed.113.130161

Do, T. M., Dodacki, A., Alata, W., Calon, F., Nicolic, S., Scherrmann, J. M., et al. (2016). Age-dependent regulation of the blood-brain barrier influx/efflux equilibrium of amyloid- $\beta$ peptide in a mouse model of Alzheimer's disease (3xTg-AD). J. Alzheimers Dis. 49, 287-300. doi: 10.3233/jad150350 
Erdő, F., Denes, L., and de Lange, E. (2017). Age-associated physiological and pathological changes at the blood-brain barrier: a review. J. Cereb. Blood Flow Metab. 37, 4-24. doi: 10.1177/0271678x16679420

Gomez-Zepeda, D., Taghi, M., Smirnova, M., Sergent, P., Liu, W. Q., Chhuon, C., et al. (2019). LC-MS/MS-based quantification of efflux transporter proteins at the BBB. J. Pharm. Biomed. Anal. 164, 496-508. doi: 10.1016/j.jpba.2018.11.013

Hartz, A. M., Miller, D. S., and Bauer, B. (2010). Restoring blood-brain barrier P-glycoprotein reduces brain amyloid- $\beta$ in a mouse model of Alzheimer's disease. Mol. Pharmacol. 77, 715-723. doi: 10.1124/mol.109.061754

Hartz, A. M. S., Zhong, Y., Shen, A. N., Abner, E. L., and Bauer, B. (2018). Preventing P-gp ubiquitination lowers $\mathrm{a} \beta$ brain levels in an Alzheimer's disease mouse model. Front. Aging Neurosci. 10:186. doi: 10.3389/fnagi.2018.00186

Hartz, A. M., Zhong, Y., Wolf, A., LeVine, H. III., Miller, D. S., and Bauer, B. (2016). A $\beta 40$ reduces P-glycoprotein at the blood-brain barrier through the ubiquitin-proteasome pathway. J. Neurosci. 36, 1930-1941. doi: 10.1523/JNEUROSCI.0350-15.2016

Hoshi, Y., Uchida, Y., Tachikawa, M., Inoue, T., Ohtsuki, S., and Terasaki, T. (2013). Quantitative atlas of blood-brain barrier transporters, receptors, and tight junction proteins in rats and common marmoset. J. Pharm. Sci. 102, 3343-3355. doi: $10.1002 /$ jps.23575

Hou, J., Liu, Q., Li, Y., Sun, H., and Zhang, J. (2014). An in vivo microdialysis study of FLZ penetration through the blood-brain barrier in normal and 6-hydroxydopamine induced Parkinson's disease model rats. Biomed. Res. Int. 2014:850493. doi: 10.1155/2014/850493

Ito, K., Uchida, Y., Ohtsuki, S., Aizawa, S., Kawakami, H., Katsukura, Y., et al. (2011). Quantitative membrane protein expression at the blood-brain barrier of adult and younger cynomolgus monkeys. J. Pharm. Sci. 100, 3939-3950. doi: $10.1002 /$ jps. 22487

Jha, N. K., Kar, R., and Niranjan, R. (2019). ABC transporters in neurological disorders: an important gateway for botanical compounds mediated neuro-therapeutics. Curr. Top. Med. Chem. doi: 10.2174/1568026619666190412121811 [Epub ahead of print].

Kalvass, J. C., Polli, J. W., Bourdet, D. L., Feng, B., Huang, S. M., Liu, X., et al. (2013). Why clinical modulation of efflux transport at the human blood-brain barrier is unlikely: the ITC evidence-based position. Clin. Pharmacol. Ther. 94, 80-94. doi: 10.1038/clpt.2013.34

Kannan, P., Schain, M., Kretzschmar, W. W., Weidner, L., Mitsios, N., Gulyas, B., et al. (2017). An automated method measures variability in P-glycoprotein and ABCG2 densities across brain regions and brain matter. J. Cereb. Blood Flow Metab. 37, 2062-2075. doi: 10.1177/0271678x16660984

Kodaira, H., Kusuhara, H., Ushiki, J., Fuse, E., and Sugiyama, Y. (2010). Kinetic analysis of the cooperation of P-glycoprotein (P-gp/Abcb1) and breast cancer resistance protein $(\mathrm{Bcrp} / \mathrm{Abcg} 2)$ in limiting the brain and testis penetration of erlotinib, flavopiridol and mitoxantrone. J. Pharmacol. Exp. Ther. 333, 788-796. doi: 10.1124/jpet.109.162321

Kuhnke, D., Jedlitschky, G., Grube, M., Krohn, M., Jucker, M., Mosyagin, I., et al. (2007). MDR1-P-glycoprotein (ABCB1) mediates transport of Alzheimer's amyloid- $\beta$ peptides-implications for the mechanisms of $A \beta$ clearance at the blood-brain barrier. Brain Pathol. 17, 347-353. doi: 10.1111/j.1750-3639.2007. 00075.x

Liow, J. S., Zoghbi, S. S., Hu, S., Hall, M. D., Hines, C. S., Shetty, H. U., et al. (2016). ${ }^{18} \mathrm{~F}$-FCWAY, a serotonin $1 \mathrm{~A}$ receptor radioligand, is a substrate for efflux transport at the human blood-brain barrier. Neuroimage 138, 134-140. doi: 10.1016/j.neuroimage.2016.05.045

Luurtsema, G., Elsinga, P., Dierckx, R., Boellaard, R., and van Waarde, A. (2016). PET tracers for imaging of $\mathrm{ABC}$ transporters at the bloodbrain barrier: principles and strategies. Curr. Pharm. Des. 22, 5779-5785. doi: 10.2174/1381612822666160810123634

Ly, J., and Maquet, P. (2014). Stroke and aging. Rev. Med. Liege. 69, 315-317.

Ma, Q., Zhao, Z., Sagare, A. P., Wu, Y., Wang, M., Owens, N. C., et al. (2018). Blood-brain barrier-associated pericytes internalize and clear aggregated amyloid- $\beta 42$ by LRP1-dependent apolipoprotein $\mathrm{E}$ isoform-specific mechanism. Mol. Neurodegener. 13:57. doi: 10.1186/s13024-018-0286-0

Michaki, V., Guix, F. X., Vennekens, K., Munck, S., Dingwall, C., Davis, J. B., et al. (2012). Down-regulation of the ATP-binding cassette transporter 2 (Abca2) reduces amyloid- $\beta$ production by altering Nicastrin maturation and intracellular localization. J. Biol. Chem. 287, 1100-1111. doi: 10.1074/jbc.m111. 288258
Nies, A. T., Jedlitschky, G., König, J., Herold-Mende, C., Steiner, H. H., Schmitt, H. P., et al. (2004). Expression and immunolocalization of the multidrug resistance proteins, MRP1-MRP6 (ABCC1-ABCC6), in human brain. Neuroscience 129, 349-360. doi: 10.1016/j.neuroscience.2004.07.051

Ohtsuki, S., Kamoi, M., Watanabe, Y., Suzuki, H., Hori, S., and Terasaki, T. (2007). Correlation of induction of ATP binding cassette transporter A5 (ABCA5) and ABCB1 mRNAs with differentiation state of human colon tumor. Biol. Pharm. Bull. 30, 1144-1146. doi: 10.1248/bpb.30.1144

Ose, A., Ito, M., Kusuhara, H., Yamatsugu, K., Kanai, M., Shibasaki, M., et al. (2009). Limited brain distribution of [3R,4R,5S]-4-acetamido-5-amino3-(1-ethylpropoxy)-1-cyclohexene-1-carboxylate phosphate (Ro 64-0802), a pharmacologically active form of oseltamivir, by active efflux across the bloodbrain barrier mediated by organic anion transporter 3 (Oat3/Slc22a8) and multidrug resistance-associated protein 4 (Mrp4/Abcc4). Drug Metab. Dispos. 37, 315-321. doi: 10.1124/dmd.108.024018

Osgood, D., Miller, M. C., Messier, A. A., Gonzalez, L., and Silverberg, G. D. (2017). Aging alters mRNA expression of amyloid transporter genes at the blood-brain barrier. Neurobiol. Aging 57, 178-185. doi: 10.1016/j. neurobiolaging.2017.05.011

Pan, Y., and Nicolazzo, J. A. (2018). Impact of aging, Alzheimer's disease and Parkinson's disease on the blood-brain barrier transport of therapeutics. Adv. Drug Deliv. Rev. 135, 62-74. doi: 10.1016/j.addr.2018.04.009

Pekcec, A., Schneider, E. L., Baumgärtner, W., Stein, V. M., Tipold, A., and Potschka, H. (2011). Age-dependent decline of blood-brain barrier P-glycoprotein expression in the canine brain. Neurobiol. Aging 32, 1477-1485. doi: 10.1016/j.neurobiolaging.2009.08.014

Pelegrí, C., Canudas, A. M., del Valle, J., Casadesus, G., Smith, M. A., Camins, A., et al. (2007). Increased permeability of blood-brain barrier on the hippocampus of a murine model of senescence. Mech. Ageing Dev. 128, 522-528. doi: 10.1016/j.mad.2007.07.002

Poller, B., Drewe, J., Krähenbühl, S., Huwyler, J., and Gutmann, H. (2010). Regulation of BCRP (ABCG2) and P-glycoprotein (ABCB1) by cytokines in a model of the human blood-brain barrier. Cell. Mol. Neurobiol. 30, 63-70. doi: 10.1007/s10571-009-9431-1

Prasad, B., and Unadkat, J. D. (2015). The concept of fraction of drug transported (ft) with special emphasis on BBB efflux of CNS and antiretroviral drugs. Clin. Pharmacol. Ther. 97, 320-323. doi: 10.1002/cpt.72

Qosa, H., Mohamed, L. A., Alqahtani, S., Abuasal, B. S., Hill, R. A., and Kaddoumi, A. (2016). Transporters as drug targets in neurological diseases. Clin. Pharmacol. Ther. 100, 441-453. doi: 10.1002/cpt.435

Ravenstijn, P. G., Merlini, M., Hameetman, M., Murray, T. K., Ward, M. A., Lewis, H., et al. (2008). The exploration of rotenone as a toxin for inducing Parkinson's disease in rats, for application in BBB transport and PK-PD experiments. J. Pharmacol. Toxicol. Methods 57, 114-130. doi: 10.1016/j.vascn. 2007.10.003

Riches, Z., Abanda, N., and Collier, A. C. (2015). BCRP protein levels do not differ regionally in adult human livers, but decline in the elderly. Chem. Biol. Interact. 242, 203-210. doi: 10.1016/j.cbi.2015.10.007

Roberts, L. M., Black, D. S., Raman, C., Woodford, K., Zhou, M., Haggerty, J. E., et al. (2008). Subcellular localization of transporters along the rat bloodbrain barrier and blood-cerebral-spinal fluid barrier by in vivo biotinylation. Neuroscience 155, 423-438. doi: 10.1016/j.neuroscience.2008.06.015

Rosati, A., Maniori, S., Decorti, G., Candussio, L., Giraldi, T., and Bartoli, F. (2003). Physiological regulation of P-glycoprotein, MRP1, MRP2 and cytochrome P450 3A2 during rat ontogeny. Dev. Growth Differ. 45, 377-387. doi: 10.1046/j. 1440-169x.2003.00699.x

Sagare, A. P., Deane, R., and Zlokovic, B. V. (2012). Low-density lipoprotein receptor-related protein 1: a physiological $A \beta$ homeostatic mechanism with multiple therapeutic opportunities. Pharmacol. Ther. 136, 94-105. doi: 10.1016/j.pharmthera.2012.07.008

Sasaki, K., Tachikawa, M., Uchida, Y., Hirano, S., Kadowaki, F., Watanabe, M., et al. (2018). ATP-binding cassette transporter a subfamily 8 is a sinusoidal efflux transporter for cholesterol and taurocholate in mouse and human liver. Mol. Pharm. 15, 343-355. doi: 10.1021/acs.molpharmaceut.7b00679

Sasongko, L., Link, J. M., Muzi, M., Mankoff, D. A., Yang, X., Collier, A. C., et al. (2005). Imaging P-glycoprotein transport activity at the human bloodbrain barrier with positron emission tomography. Clin. Pharmacol. Ther. 77, 503-514. doi: 10.1016/j.clpt.2005.01.022 
Schinkel, A. H., Smit, J. J., van Tellingen, O., Beijnen, J. H., Wagenaar, E., van Deemter, L., et al. (1994). Disruption of the mouse mdrla P-glycoprotein gene leads to a deficiency in the blood-brain barrier and to increased sensitivity to drugs. Cell 77, 491-502. doi: 10.1016/0092-8674(94)90212-7

Sedykh, A., Fourches, D., Duan, J., Hucke, O., Garneau, M., Zhu, H., et al. (2013). Human intestinal transporter database: QSAR modeling and virtual profiling of drug uptake, efflux and interactions. Pharm. Res. 30, 996-1007. doi: 10.1007/s11095-012-0935-x

Sharma, H. S., Castellani, R. J., Smith, M. A., and Sharma, A. (2012). The bloodbrain barrier in Alzheimer's disease: novel therapeutic targets and nanodrug delivery. Int. Rev. Neurobiol. 102, 47-90. doi: 10.1016/B978-0-12-386986-9. 00003-X

Shawahna, R., Uchida, Y., Decleves, X., Ohtsuki, S., Yousif, S., Dauchy, S., et al. (2011). Transcriptomic and quantitative proteomic analysis of transporters and drug metabolizing enzymes in freshly isolated human brain microvessels. Mol. Pharm. 8, 1332-1341. doi: 10.1021/mp200129p

Shibata, M., Yamada, S., Kumar, S. R., Calero, M., Bading, J., Frangione, B., et al. (2000). Clearance of Alzheimer's amyloid-ss(1-40) peptide from brain by LDL receptor-related protein-1 at the blood-brain barrier. J. Clin. Invest. 106, 1489-1499. doi: 10.1172/JCI10498

Storck, S. E., Hartz, A. M. S., Bernard, J., Wolf, A., Kachlmeier, A., Mahringer, A., et al. (2018). The concerted amyloid- $\beta$ clearance of LRP1 and ABCB1/P-gp across the blood-brain barrier is linked by PICALM. Brain Behav. Immun. 73, 21-33. doi: 10.1016/j.bbi.2018.07.017

Syvänen, S., and Eriksson, J. (2013). Advances in PET imaging of P-glycoprotein function at the blood-brain barrier. ACS Chem. Neurosci. 4, 225-237. doi: $10.1021 / \mathrm{cn} 3001729$

Sziráki, I., Erdö, F., Beéry, E., Molnár, P. M., Fazakas, C., Wilhelm, I., et al. (2011). Quinidine as an ABCB1 probe for testing drug interactions at the blood-brain barrier: an in vitro-in vivo correlation study. J. Biomol. Screen. 16, 886-894. doi: $10.1177 / 1087057111414896$

Sziráki, I., Erdö, F., Trampus, P., Sike, M., Molnár, P. M., Rajnai, Z., et al. (2013). The use of microdialysis techniques in mice to study P-gp function at the bloodbrain barrier. J Biomol Screen 18, 430-440. doi: 10.1177/1087057112468156

Thiollier, T., Wu, C., Contamin, H., Li, Q., Zhang, J., and Bezard, E. (2016). Permeability of blood-brain barrier in macaque model of 1-methyl-4-phenyl1,2,3,6-tetrahydropyridine-induced Parkinson disease. Synapse 70, 231-239. doi: 10.1002/syn.21889

Toornvliet, R., van Berckel, B. N., Luurtsema, G., Lubberink, M., Geldof, A. A., Bosch, T. M., et al. (2006). Effect of age on functional P-glycoprotein in the blood-brain barrier measured by use of $(R)-\left[{ }^{11} \mathrm{C}\right]$ verapamil and positron emission tomography. Clin. Pharmacol. Ther. 79, 540-548. doi: 10.1016/j.clpt. 2006.02.004

Trapa, P. E., Troutman, M. D., Lau, T. Y., Wager, T. T., Maurer, T. S., Patel, N. C., et al. (2019). In vitro-in vivo extrapolation of key transporter activity at the blood-brain barrier. Drug Metab. Dispos. 47, 405-411. doi: 10.1124/dmd.118. 083279

Uchida, Y., Ohtsuki, S., Kamiie, J., and Terasaki, T. (2011a). Blood-brain barrier (BBB) pharmacoproteomics: reconstruction of in vivo brain distribution of 11
P-glycoprotein substrates based on the BBB transporter protein concentration, in vitro intrinsic transport activity and unbound fraction in plasma and brain in mice. J. Pharmacol. Exp. Ther. 339, 579-588. doi: 10.1124/jpet.111.184200

Uchida, Y., Ohtsuki, S., Katsukura, Y., Ikeda, C., Suzuki, T., Kamiie, J., et al. (2011b). Quantitative targeted absolute proteomics of human blood-brain barrier transporters and receptors. J. Neurochem. 117, 333-345. doi: 10.1111/j. 1471-4159.2011.07208.x

Ueno, M., Akiguchi, I., Yagi, H., Naiki, H., Fujibayashi, Y., Kimura, J., et al. (1993). Age-related changes in barrier function in mouse brain I. Accelerated age-related increase of brain transfer of serum albumin in accelerated senescence prone SAM-P/8 mice with deficits in learning and memory. Arch. Gerontol. Geriatr. 16, 233-248. doi: 10.1016/0167-4943(93)90035-g

van Assema, D. M., Lubberink, M., Boellaard, R., Schuit, R. C., Windhorst, A. D., Scheltens, P., et al. (2012). P-glycoprotein function at the blood-brain barrier: effects of age and gender. Mol. Imaging Biol. 14, 771-776. doi: 10.1007/s11307012-0556-0

Vilas-Boas, V., Silva, R., Gaio, A. R., Martins, A. M., Lima, S. C., Cordeiroda-Silva, A., et al. (2011). P-glycoprotein activity in human Caucasian male lymphocytes does not follow its increased expression during aging. Cytometry A 79, 912-919. doi: 10.1002/cyto.a.21135

Vogelgesang, S., Jedlitschky, G., Brenn, A., and Walker, L. C. (2011). The role of the ATP-binding cassette transporter P-glycoprotein in the transport of $\beta$-amyloid across the blood-brain barrier. Curr. Pharm. Des. 17, 2778-2786. doi: 10.2174/138161211797440168

Vogelgesang, S., Warzok, R. W., Cascorbi, I., Kunert-Keil, C., Schroeder, E., Kroemer, H. K., et al. (2004). The role of P-glycoprotein in cerebral amyloid angiopathy; implications for the early pathogenesis of Alzheimer's disease. Curr. Alzheimer Res. 1, 121-125. doi: 10.2174/1567205043332225

von Wedel-Parlow, M., Wölte, P., and Galla, H. J. (2009). Regulation of major efflux transporters under inflammatory conditions at the blood-brain barrier in vitro. J. Neurochem. 111, 111-118. doi: 10.1111/j.1471-4159.2009.06305.x

Wu, B., Ueno, M., Onodera, M., Kusaka, T., Huang, C. L., Hosomi, N., et al. (2009). Age-related changes in P-glycoprotein expression in senescence-accelerated mouse. Curr. Aging Sci. 2, 187-192. doi: 10.2174/1874609810902030187

Zhang, Y., Schuetz, J. D., Elmquist, W. F., and Miller, D. W. (2004). Plasma membrane localization of multidrug resistance-associated protein homologs in brain capillary endothelial cells. J. Pharmacol. Exp. Ther. 311, 449-455. doi: 10.1124/jpet.104.068528

Conflict of Interest Statement: The authors declare that the research was conducted in the absence of any commercial or financial relationships that could be construed as a potential conflict of interest.

Copyright (c) 2019 Erdö and Krajcsi. This is an open-access article distributed under the terms of the Creative Commons Attribution License (CC BY). The use, distribution or reproduction in other forums is permitted, provided the original author(s) and the copyright owner(s) are credited and that the original publication in this journal is cited, in accordance with accepted academic practice. No use, distribution or reproduction is permitted which does not comply with these terms. 